\title{
An ACO-Based Algorithm for Solving Path Planning Problem of Cyclic Goods-Taking
}

\author{
Yikui Mo ${ }^{\mathrm{a}}$, Cheng Gong ${ }^{\mathrm{a}}$, Shen $\mathrm{Lv}^{\mathrm{c}}$ \\ College of Civil Engineering, Shenzhen University, Nanhai Road 3688, Shenzhen, China

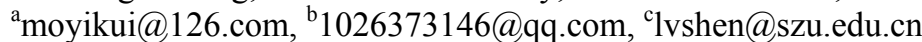

\begin{abstract}
Based on the analysis of the path planning under the cyclic goods-taking model, the mathematical model of path planning is established. After comparison and analysis of the commonly-used optimization algorithms, the Ant Colony Optimization (ACO) is adopted to solve the path planning model under the situation of cyclic goods-taking model. An auto manufacturing plant is adopted as a case, with its cyclic goods-taking path of its parts entering the plant being planned. Research finds that a satisfying transportation path under the cyclic goods-taking model with reduced transportation costs can be obtained through the ACO-based path planning.
\end{abstract}

Keywords- ant colony optimization; algorithm; path planning problem; cyclic goods-taking

\section{INTRODUCTION}

Cyclic goods-taking is also called "Milk Run," which means a vehicle goes to the designated goods-taking site to fetch a fixed amount of goods and return to the starting point. The cyclic goods-taking model will not cause the problem of unloaded vehicles, thus greatly reducing the transportation cost. It is especially suitable for auto, machinery and other industrial enterprises, because it can ensure the supply of parts on schedule and up to the required quantity, and the realization of in-time production.

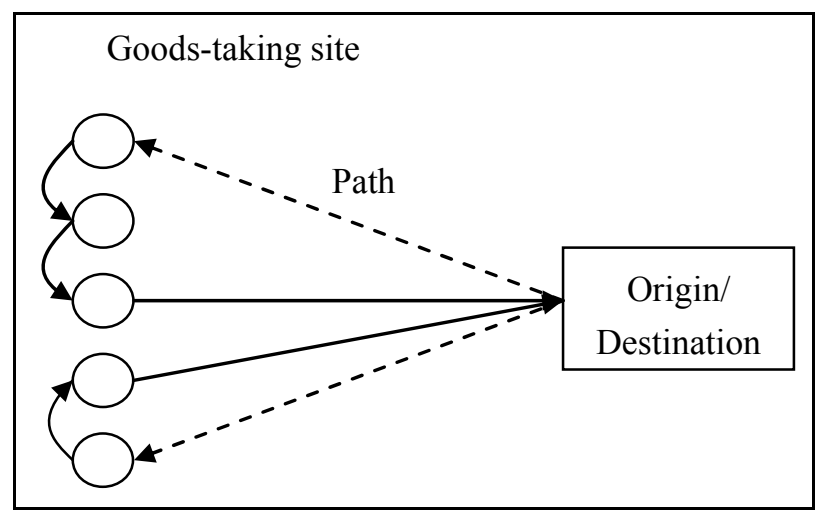

Figure 1. Cyclic goods-taking model

To put it specifically, cyclic goods-taking model has the following advantages:

(1) Realize multi-batch, small-quantity and standardized supply and reduce the inventory cost of enterprises;

(2) Improve the vehicle's unloading rate and reduce the transportation cost because it does not has the problem of empty vehicle on the returned journey compared with the inbound logistics model featuring the direct delivery by the supplier;

(3) Benefit different parties in the supply chain and finally reduce the product cost.

\section{PATH PLANNING OF CYCLIC GOODS-TAKING}

\section{A. Path planning problem of cyclic goods-taking}

The issue of path planning under the cyclic goodstaking model can be described as: in a system, there is a starting point which is also a finishing point; there are several goods-taking sites to fetch goods and the professional third party logistics company is responsible for arranging several vehicles to start from several starting points to fetch goods in several goods-taking sites and send goods to destinations. The position of every goods-taking site and the load capacity of every vehicle (or the loading volume) are fixed. The number of vehicles and the goodstaking path of every vehicle should be confirmed so as to minimize the overall transportation costs.

\section{B. Hypothesis conditions}

The issue of path planning under the cyclic goodstaking model should meet the following hypothesis conditions:

(1) The goods-taking vehicle starts from the starting point and returns to the starting point after finishing the goods-taking.

(2) The number of goods to be taken from every goodstaking site should be given.

(3) The goods in every goods-taking site should be taken at once;

(4) The cargo capacity of every goods-taking site is fixed and should not be overloaded during the transportation process.

(5) There are connectable roads between the starting point and every goods-taking site, and between goodstaking sites.

(6) The number of vehicles is adequate and free of limits.

\section{MODELING FOR THE PATH PLANNING PROBLEM OF CYCLIC GOODS - TAKING}

\section{A. Path planning modeling for the cyclic goods-taking}

The issue of path planning under the cyclic goodstaking model can be expressed by the following model: 


$$
\operatorname{MinZ}=\sum_{i=0}^{n} \sum_{j=0}^{n} \sum_{k=1}^{m} d_{i j} x_{i j k}
$$

s.t.

$$
\begin{gathered}
\sum_{i=0}^{n} q_{i} y_{k i} \leq Q, \quad k=1,2, \ldots, m \\
\sum_{k=1}^{m} y_{k i}=1, \quad k=1,2, \ldots, m \\
\sum_{i=0}^{n} y_{i j k}=y_{k j}, k=1,2, \ldots m ; j=0,1,2 \ldots, n \\
\sum_{j=0}^{n} y_{i j k}=y_{k i}, k=1,2, . . m ; i=0,1,2 \ldots, n \\
x_{i j k}=0 \text { or } 1, k=1,2, \ldots m ; i, j=0,1,2 \ldots, n \\
y_{i j k}=0 \text { or } 1, k=1,2, \ldots m ; i, j=0,1,2 \ldots, n
\end{gathered}
$$

From the above model, it can be seen that $Z$ stands for the total driving distance of the vehicle; $k$ stands for the vehicle; $m$ stands for the number of vehicles; $q_{i}$ stands for the number of goods taken from the goods-taking site $i ; Q$ stands for the maximum loading of the vehicle; $d_{i j}$ stands for the distance from the goods-taking site $i$ to the goodstaking site $j$; and $i(i=0)$ stands for the serial number of the starting and finishing points, while the serial number $i$ of the goods-taking site is $i=1,2,3 \ldots \mathrm{n}$.

(1) means that the objective function of the model is the shortest driving distance of all vehicles in the cyclic goods-taking. (2) means that the dead weight capacity of every vehicle exceeds the rated loading capacity of the vehicle. (3) means that every goods-taking site has the vehicle to fetch goods. (4) and (5) means that only one vehicle will go to each goods-taking site; (6) and (7) stands for the value range of two variables.

\section{SOLUTION ALGORITHM}

According to the characteristics of the path planning issue, the ACO is adopted as the solution algorithm for the model in this paper.

The solution process can be divided into two periods. First, the heuristic algorithm, such as the scanning methods, can be adopted to work out a feasible solution. Then, the feasible solution is optimized through the ACO to obtain an optimal solution.

The ACO-based solution of the path planning issue manly follows the following steps:

(1) Initialize parameters: Set the cyclic number $N_{c}=0$, the maximum cyclic number as $N_{\text {cmax }}$; put ' $\mathrm{K}$ ' $(\mathrm{K}=1,2,3 \ldots \mathrm{n})$ ants in the goods-taking network; ensure the initialized information amount of every side $(i, j)$ of the directed graph to be $\tau_{i j}(t)=C$ where $\mathrm{C}$ stands for the constant and $\Delta \tau_{i j}(0)=0$ at the initial moment;

(2) The cycle index: $N_{c} \leftarrow N_{c}+1$;

(3) The index number of the tabu table: $k=1$;

(4) The number of ants: $k \leftarrow k+1$;
(5) Individual ants choose the goods-taking site, j, according to the calculated probability and move ahead;

(6) Modify the tabu table (in other words, move ants to the new goods-taking site after choice is made, and move the goods-delivery site to the individual tabu table of the ants);

(7) If there are some goods-taking sites which have not yet been found by ants, namely $k<m$, return to Step (4); otherwise, return to Step 8);

(8) Update the information quantity of every path;

(9) If the end condition is met, namely $N_{c}>N_{c \max }$, the cycle ends and the routine calculation result is output; otherwise, the tabu table is emptied and return to Step 2).

\section{CASe STUdy}

\section{A. Basic data}

A automobile factory is adopted as a case and marked as 'A' to study the parts distribution path planning of 15 suppliers. Every of the 15 suppliers provide a fixed amount of parts to A. The daily supply quantity of every supplier every day is shown in Table 1:

TABLE I. SUPPLY QUANTITY OF VARIOUS SUPPLIERS

\begin{tabular}{|c|c|c|c|}
\hline Supplier & $\begin{array}{c}\text { Supply Quantity } \\
\mathbf{( m}^{\mathbf{3}} \mathbf{)}\end{array}$ & Supplier & $\begin{array}{c}\text { Supply } \\
\text { Quantity } \\
\mathbf{( m}^{\mathbf{3}} \mathbf{)}\end{array}$ \\
\hline 1 & 11.69 & 9 & 19.87 \\
\hline 2 & 8.83 & 10 & 9.98 \\
\hline 3 & 18.61 & 11 & 26.40 \\
\hline 4 & 15.66 & 12 & 27.84 \\
\hline 5 & 15.29 & 13 & 32.63 \\
\hline 6 & 27.37 & 14 & 11.57 \\
\hline 7 & 19.28 & 15 & 35.94 \\
\hline 8 & 10.47 & & \\
\hline
\end{tabular}

The position of automobile factory is (31.3113580172 121.2046952052).

The position information (longitude and latitude) of various suppliers is listed below:

TABLE II. LONGITUDE AND LATITUDE OF VARIOUS SUPPLIERS

\begin{tabular}{|c|c|c|}
\hline Supplier & Longitude & Latitude \\
\hline 1 & 31.3585807424 & 121.2444253319 \\
\hline 2 & 31.3388371285 & 121.0401943363 \\
\hline 3 & 31.3168206986 & 121.0176441210 \\
\hline 4 & 31.4677213199 & 121.1904894005 \\
\hline 5 & 31.3548730000 & 121.0437840000 \\
\hline 6 & 31.1751601901 & 121.1496232868 \\
\hline 7 & 31.4900762219 & 121.1173215085 \\
\hline 8 & 31.4823070000 & 121.1543740000 \\
\hline 9 & 31.3493844351 & 121.4351300335 \\
\hline 10 & 31.1816894787 & 121.0306673626 \\
\hline
\end{tabular}




\begin{tabular}{|l|l|l|}
\hline 11 & 31.1841566973 & 121.4036055796 \\
\hline 12 & 31.0779899573 & 121.3893935122 \\
\hline 13 & 31.2892298288 & 120.8946188334 \\
\hline 14 & 31.3177598157 & 120.7952056014 \\
\hline 15 & 31.1488211588 & 121.5669851918 \\
\hline
\end{tabular}

The volume of the transportation vehicle is 61 square meters. There are connected roads between the manufacturing plant and suppliers, and between suppliers. The influence of the transportation situation is not taken into consideration.

\section{B. Initial Solution Based on the Scanning Method}

A feasible solution is obtained through the scanning method. The driving path and distance of different vehicles in the feasible solution is shown in Table 3.

TABLE III. THE INITIAL FEASIBLE SOLUTION

\begin{tabular}{|c|c|c|}
\hline & Driving Path & Driving Distance \\
\hline 1 & $(\mathrm{~A}-1-9-10-\mathrm{A})$ & 125.7 \\
\hline 2 & $(\mathrm{~A}-11-4-2-\mathrm{A})$ & 142.6 \\
\hline 3 & $(\mathrm{~A}-8-3-7-\mathrm{A})$ & 119.6 \\
\hline 4 & $(\mathrm{~A}-5-6-\mathrm{A})$ & 78.3 \\
\hline 5 & $(\mathrm{~A}-13-14-\mathrm{A})$ & 112 \\
\hline 6 & $(\mathrm{~A}-15-\mathrm{A})$ & 83.6 \\
\hline 7 & $(\mathrm{~A}-12-\mathrm{A})$ & 774.3 \\
\hline $\begin{array}{c}\text { Total } \\
\text { Distance }\end{array}$ & & \\
\hline
\end{tabular}

From the above table, it can be seen that the initial solution obtained through scanning has seven driving paths, which total at $774.3 \mathrm{~km}$.

\section{The Optimal Solution Obtained Through the ACO}

The parameters in the ACO: $m=50, \alpha=1, \beta=1, \rho=0.5$; $N c=100, Q=100$.

As is shown in Fig. 1, when the iteration is around 46times, the objective function value tends to be stable. The value of the minimum objective function (1) is $657 \mathrm{~km}$.

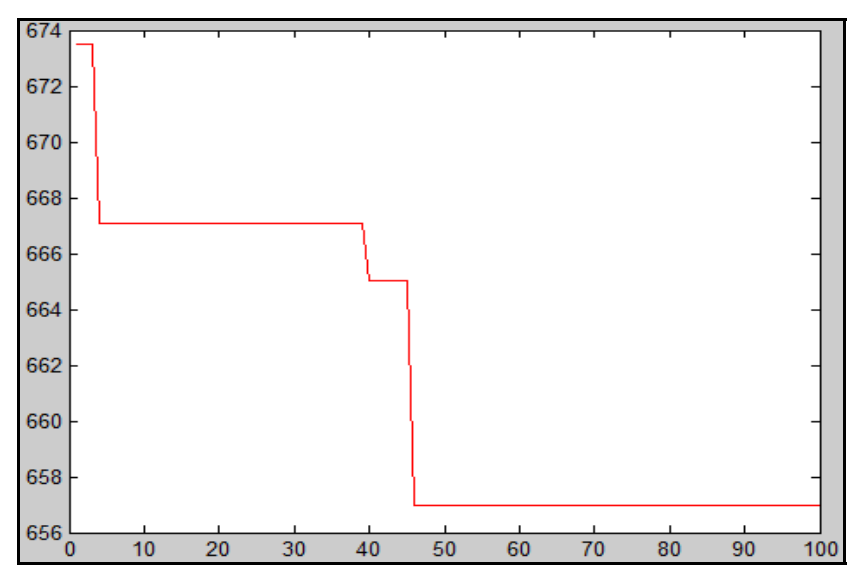

Figure 2. The iterative process

There are seven paths in total. In the optimal solution, the driving distance of every vehicle and the total driving distance are shown in Table 4.

TABLE IV. THE OPTIMAL SOLUTION

\begin{tabular}{|c|c|c|}
\hline & Driving Path & Driving Distance \\
\hline 1 & (A-1-8-A) & 57.7 \\
\hline 2 & (A-12-11-A) & 93.4 \\
\hline 3 & (A-3-10-A) & 73.8 \\
\hline 4 & (A-13-6-A) & 110.5 \\
\hline 5 & (A-5-2-A) & 49.1 \\
\hline 6 & $($ A-15-9-A) & 122.4 \\
\hline 7 & $($ A-4-14-7-A) & 150.1 \\
\hline $\begin{array}{c}\text { Total } \\
\text { Distance }\end{array}$ & & 657 \\
\hline
\end{tabular}

There are seven goods-taking paths, which mean that seven vehicles are needed. However, comparatively speaking, the total path optimized through the ACO is shorter, which means the reduction of transportation time and costs.

\section{CONCLUSIONS}

This paper adopts the path planning issue under the cyclic goods-taking delivery as the research object, analyzing its advantages, disadvantages and implementation conditions. Based on the full consideration of major influencing factors, the optimized mathematical model of the path planning under the cyclic goods-taking model is established. Through comparing and analyzing the major algorithms, the ACO is adopted to solve the path planning issue under the cyclic goods-taking model.

The parts inbound logistics of certain auto manufacturer is adopted as the research object to verify the mathematical model and the solution algorithm put forward by this paper. The research findings showed that the mathematical model and the solution algorithm based on the ACO are highly practical and can help efficiently decrease the transportation cost. 
During the model building process, this paper ignores many factors influencing the path planning, such as the goods-taking time, the road connection, the vehicle running speed and so on. These factors can be further studied in the future.

\section{ACKNOWLEDGMENT}

This research was supported by Project 51208308 supported by NSFC, Project 51208307 supported by NSFC, Science and Technology Projects of Transportation Department of Guangdong Province (No. 2012-02-055).

\section{REFERENCES}

[1] G.Svensson, "The impact of outsourcing on inbound logistics flows," International Journal of Logistics Management, vol.12, pp.21-35, 2001.

[2] G.Svensson, "A conceptual framework of vulnerability in firms' inbound and outbound logistics flow," International Journal of Physical Distribution and Logistics Management, vol.32, pp.110134,2002 .

[3] H.L.Richardson, "Big checkbooks make for big clout," Transportation and Distribution. vol.6, pp.30-34, 2003.
[4] J.Miemczyk, M. Holweg, "Building cars to customer order-what does it means for inbound logistics operations," Journal of business logistics, vol.25, pp. 171-198, 2004.

[5] M.Lijima, S.Sugawara, "Logistics innovation for Toyota's world car strategy," International Journal of Integrated Supply Management, vol.4, pp.478-489, 2005.

[6] C.L.Li, G.Vairaktarakis, "Coordinating production and distribution of jobs with bundling operations,'IIE Transactions, vol.39, pp.203215, 2007.

[7] L.F.Peace, "The next step for a lean production: Milk Run," SAE Technical Paper Series, vol.32, pp.10-12, 2000.

[8] T.Du, F.K.Wang, P.Y.Lu, "A real time vehicle-dispatching system for consolidating milk-runs," Transportation Research part E: Logistics and Transportation Review, vol.43, pp.565-577, 2007.

[9] D.Ramserj, "The truck dispatching problem," Management Science, vol.6, pp.81-90,1959.

[10] J.Stacey, M. Natarajaraathinam, C.Sox, "The storage constrained, inbound inventory routing problem," International Journal of Physical Distribution \& Logisitics Management, vol.36, pp.484$500,2007$.

[11] J.W.Ohlmann, M.J.Fry, B.W.Thomas, "Route design for lean Production systems," Transportation Science, vol.42, pp.352370,2008 